\title{
A comparison of Speech Duration in Cochlear Implant and Normal Hearing Elementary School Students in the Imitation and Reading Tasks
}

\author{
Marzieh Hasanvand ${ }^{1}$, Farhad Torabinezhad ${ }^{2 *}$, Jamileh Abolghasemi ${ }^{3}$, Moharram Eslami ${ }^{4}$ \\ 1. Speech and Language Pathologist, Department of Speech and Language Pathology, School of Rehabilitation Sciences, \\ Iran University of Medical Sciences, Tehran, Iran \\ 2. Assistant Professor, Department of Speech and Language Pathology, School of Rehabilitation Sciences, Iran University \\ of Medical Sciences, Tehran, Iran \\ 3. Assistant Professor, Department of Biostatistics, School of Public Health, Iran University of Medical Sciences, Tehran, \\ Iran \\ 4. Associate Professor, Department of Persian Language and Literature, University of Zanjan, Zanjan, Iran
}

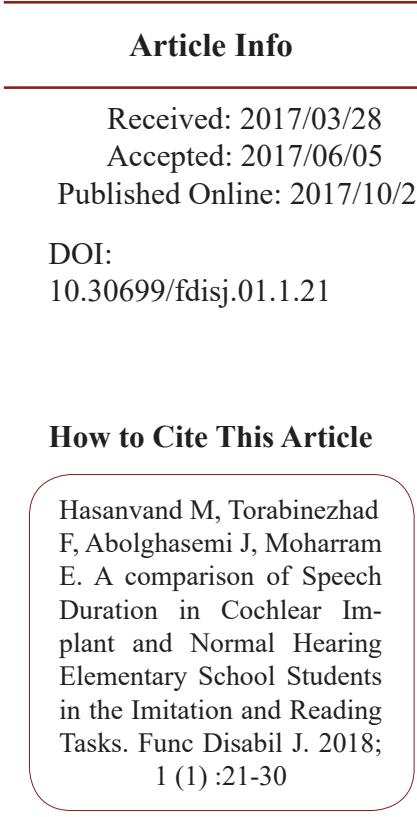

Use your device to scan and read the article online

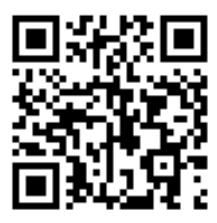

\section{ABSTRACT}

Background and Objectives: Excessive duration is one of the suprasegmental features in cochlear implant children. Regarding the importance of the normal rate of speech in transferring the intonation and clarity of speech, the present study aims at comparing word and sentence duration in cochlear implant and normal hearing children in imitation and reading tasks.

Methods: The present descriptive-analytical study was performed on 30 elementary school cochlear implant children versus 30 normal hearing children. Voice recording was done in a silent room. The Persian-speaking subject was asked to utter "/ sælam/ (hello)" and “/Pemruz nemiyad/ (He won't come today)" with the following moods and emotions: statement, question, exclamation, with happiness and with sadness. Then, they were asked to do the same task imitating the voice which had been recorded earlier. Data recording was done using Praat software and data analysis was done by SPSS software.

Results: The average duration in cochlear implant children in two modes of imitating and reading a word showed a significant difference with that of children with normal hearing $(P<0.001)$. Moreover, in both groups, the average duration of reading the word was less in comparison with imitating the word. Also, the average duration in cochlear implant children in two modes of imitating and reading a sentence showed a significant difference with that of children with normal hearing $(P<0.001)$. In the cochlear implant group, the average duration of imitating the sentence was less than the average duration of reading the sentence, whereas in the normal hearing group, the average duration of reading the sentence was less than the average duration of imitating the sentence.

Conclusion: The average duration in cochlear implant in all modes (word imitation, word reading, sentence imitation, sentence reading) was more than normal hearing children, which results in abnormal intonation in these children. According to the present study, imitation cannot cause a decrease in duration and consequently, does not result in more natural intonation. Hence, it is probably not a proper therapeutic method.

Keywords: Speech duration, Cochlear implant, Normal hearing, Imitation, Reading, Persian 


\section{Introduction}

One of the most important senses to acquire speech is hearing. Researchers believe that the infant is able to process sounds around him from birth, so that he will be able to acquire speech and learn the language by reliance on the sense of hearing (Werner, 2007). In children with hearing impairment, the deficiency in verification of audible information, particularly in pre-lingual period, leads to speech disorders. The reason is that in addition to neurotic-muscular control, hearing is essential for the appropriate performance in oral communication (Coelho, Brasolotto, Bevilacqua, Moret \& Júnior, 2015). Therefore, the reinforcement of hearing has been emphasized in children with hearing impairment (Abbasian Nik, Hassanzadeh, \& Ghobaribonab, 2013). In recent years, progress in technology and hearing-aid equipment has paved the way to enhance hearing performance.As a result, this also reinforced linguistic skills as well as speech (Ashoori, Hasanzadeh, \& Pourmohamadreza Tajrishi, 2013). Cochlear implant is a kind of common surgery in the world which is used to reinforce the sense of hearing in people with intense or deep hearing impairment. The operation includes implanting an electronic device inside the inner ear that functions as hearing aid equipment for them (Shankar, 2015). This device enables many congenial or pre-lingual deaf children to hear and understand speech and acquire their mother language (Wang, Trehub, Volkova, \& van Lieshout, 2013). Since cochlear implant is a hearing substitute whose most specific advantage is hearing and perceiving sounds and consequently leading to better and more natural production of speech sounds, it is best that this operation be done at an earlier ages (Roohparvar, Bijankhan, Hasanzadeh, \& Jalaie, 2010). Cochlear implant facilitates perception of speech and gives a substantial help to the advancement of different aspects of speech production, including increasing speech clarity, consonant production, vowel production, and speech prosody (Jafary, 2012).

Prosody is defined as the suprasegmental feature of speech. Speech intonation is one of the most important components of speech prosody whose parameters include fundamental frequency, intensity, and duration (Chin, Bergeson, \& Phan, 2012). Every moment, hearing feedback is important in controlling the suprasegmental features of speech such as fundamental frequency, intensity, and duration (Angelocci, Kopp, \& Holbrook, 1964). Children with normal hearing acquire speech prosody features before they could utter two-word phrases and are able to produce falling intonation properly up to 80 percent (Snow, 2001). However, imperfect hearing feedback in children with hearing impairment hinders them from forming normal intonation (Chin, 2012). Despite the mentioned advantages of cochlear implant, children with cochlear implant display major defects in the production of prosody, particularly intonation (Nakata, Trehub, \& Kanda, 2012) because such devices provide limited information concerning the temporal and categorical features of speech (Wang, Trehub, Volkova, \& van Lieshout, 2013; Nakata, Trehub, \& Kanda, 2012).

Some suprasegmental errors that occur in children with hearing impairment include: excessive duration, low rate of speech, and abnormal changes of intonation (Hide, Gillis, \& Govaerts, 2007; Bochner, Snell, \& MacKenzie, 1988; Lenden \& Flipsen, 2007). Duration means the time needed to produce each unit of language or a speech sample which is calculated by millisecond and is one of the major components of speech intonation that if damaged, the speech produced by impaired hearing becomes significantly unclear (Jafary, Yadegari, \& Torabineghad, 2014; Cruttenden 1997; Mardani, Safaeyan, Tavakoli, Sobhani, \& Ghaemi, 2014). By using duration, some paralinguistic information like confirmation and denial could be realized (Ishi, Ishiguro, \& Hagita, 2008). In some languages such as Arabic, duration functions as a phoneme component which leads to semantic contrast, whereas in Persian the duration is only a phonetic feature which leads to changes in intonation (Nikravesh, Torabinezhad, Ghorbani, \& Keyhani, 2012).

Despite the importance of duration in intonation and clarity of speech in children with hearing disorders, a few researches in this field have been carried out in recent years in IRAN. For instance, Kord et al. investigated the acoustic correlations of intonation 
in sentences and statements in 50 elementary school students. According to the findings of their research, speech duration in cochlear implant children is significantly more than normal children (Kord, Shahbodaghi, Khodami, Nourbakhsh, \& Jalaei, 2013). Jafary et al. compared vowel duration in Persian, in 20 pre-lingual cochlear children and 20 normal hearing children aged 5-9 years old. The words included /bid/, /bed/, /bud/, / $\mathrm{bod} /$, /bad/ \& /bæd/. The results showed that duration of 6 Persian vowels in cochlear implant children was longer than the duration of the same vowels in normal children (Jafary, Yadegari, \& Torabineghad, 2014). In a study, Clark showed that the duration and pause in utterances of cochlear implant children is more than in normal children, particularly as the number of syllables increases (Clark, 2007). Vandam et al. showed that vowel duration in words in children with hearing aids and cochlear implant is longer than that of normal children, while children with hearing aids and cochlear implants did not perform differently from each other (Vandam, Ide-Helvie, \& Moeller, 2011). Also, Uchanski and Geers realized that vowel duration in sentences in cochlear implant children is 132 milliseconds longer than vowel duration with normal hearing (Uchanski \& Geers, 2003). In a study, O'Haplin showed that speech length in cochlear implant children is significantly longer than in normal children (O'Halpin, 2010). Levitt and Osberger showed that vowel duration in continuous speech in children with hearing problems is longer than vowel duration in normal children (Osberger \& Levitt, 1979).

The present study aims at studying and comparing word and sentence duration in cochlear implant and normal hearing elementary school students in the tasks of reading and imitation. Two tasks were chosen so as to find an answer to the following question: does giving the right pattern in the form of imitation cause a change in speech duration of cochlear implant children?

\section{Material and Methods}

The current study is descriptive-analytic and it is applied through a cross-sectional and non-interventional investigation done on 30 cochlear implant (10.3 \pm
$0.39)$ and 30 normal hearing $(10 \pm 0.31)$ elementary school students. The samples were selected from children who referred to MAHASH clinic as well as the children who were studying in hearing impairment schools and children attending normal schools in the city of Tehran, Iran, along with considering the age parameter of the participants.

The provisions for including all the children in the study were the following: normal IQ, being monolingual, and being elementary school students. In addition to these, the provisions based on which cochlear implant children were included in the study were: congenital hearing problems or before learning language, one-sided cochlear implant, and having passed rehabilitation and speech therapy courses. The criteria to be excluded from the study for both groups were a record of having neurotic-muscular illnesses, having structural and movement disorders in speaking organs, physical or mental disabilities which cause malfunction in doing the tasks, diseases such as epilepsy and seizure, bilingualism, or having cold or respiratory diseases.

Sampling and voice recording was done in a silent room. Each subject was asked to sit on a chair in a way that they prevent the head or neck from turning to sides or upward/downward as much as possible. Voice recording was done by a condenser microphone connected to an ASUS X452L laptop and using Praat software (version 5.2.15). In order to decrease the noise, the microphone was set and fixed 5 to 10 centimeters from the subjects' mouths. To make sure that the subject is speaking in his routine constant voice, the sampling was done after at least two hours after waking up.

Before sampling, the subject was given a list of the intended tasks so that he could read them as a practice and also get familiar with these tasks. To make the subject ready for voice recording, he/she was asked to produce the vowel /a/ continuously for some seconds. Then the subject was given "/sælam/ (Hello)" and "/Pemruz nemiyad/ (He won't come today)" [taken from a study done by Nikravesh et al. (Nikravesh, Aghajanzade, 2011)] and was asked to read them with the following moods and emotions: exclamation, sad- 
ness, happiness, question, and statement. To guide the subject through different ways of articulation, the following emotions and sign were used: surprised, sad, happy, and question mark (?). In the next step, the subject was given a break and reward and was asked to do the same tasks by imitating the voices which had been recorded before.

Upon completion, the audio samples were TextGrided using Praat software. Then, by use of the proper script, the duration related to each sample was extracted. Statistical data analysis was done using SPSS (version 22).

\section{Results}

The repeated measurement analysis indicated that the mean duration to produce "/sælam/" in different modes of imitation and reading had significant difference between the two groups (P-Value $<0.001)$. As it can be seen in figure 1, the mean duration to produce "/sælam/" in all modes of imitation and reading in the cochlear implant group was longer than that of the normal group. Also, in the two groups as studied separately, the mean duration of "/sælam/" in different modes showed a significant difference (P-Value $<$ $0.001)$. According to tables 2 and 3, the longest duration time in the two groups was that of exclamation imitation, the shortest duration time in the cochlear implant group was that of reading in exclamation emotion, and the shortest duration time in normal hearing group was that of reading in statement mood. Also, it was observed that in both groups, mean duration in reading mode was less than that of imitation mode.

Mean duration of the sentence "/Pemruz nemiyad/" in different modes of imitation and reading showed a significant difference between the two groups (P-Value $<0.001)$. As it can be observed in figure 2 , mean duration of "/Pemruz nemiyad/" in imitation as well as reading mode in the cochlear implant group was longer than that of the normal hearing group. Moreover, in the two groups as studied separately, the mean duration of "/Pemruz nemiyad/" in different modes showed a significant difference (P-Value $<0.001)$. According to tables 2 and 3 , the longest duration time in the cochlear implant group was that of reading in sad emotion, and the shortest duration time was that of imitation in statement mood. On the other hand, the longest duration time in the normal group was that of imitation in happiness emotion, and the shortest duration time was that of reading in statement mood. The comparison of mean duration of the sentence in reading and imitation showed that in the cochlear implant group, mean duration of the sentence in imitation was less than reading, while in the normal hearing group sentence duration in reading was less than imitation.

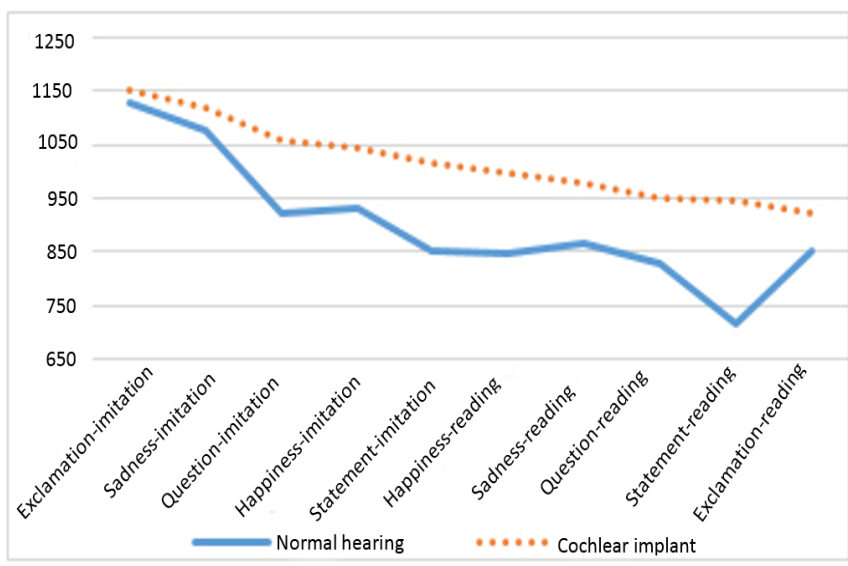

Diagram 1. The comparison of mean duration of "/scelam/" in the two groups in different moods and emotions of imitation and reading by millisecond

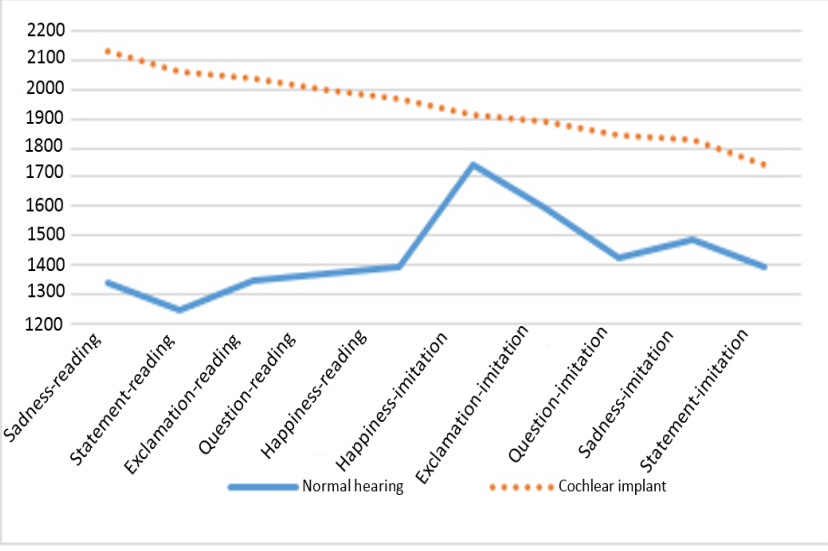

Diagram 2. The comparison of mean duration of "/emruz nemiyad/" in the two groups in different moods and emotions of imitation and reading by millisecond 
25. A comparison of Speech Duration in Cochlear Implant ...

Table 1. Mean and standard deviation of duration of "/scelam/" and "Pemruz nemiyad/" in different moods and emotions in imitation and reading in the two groups by millisecond

\begin{tabular}{|c|c|c|c|c|}
\hline & & & Cochlear Implant & Normal Hearing \\
\hline mood/emotion & Task & Type & Mean (SD) & Mean (SD) \\
\hline \multirow{4}{*}{ exclamation } & \multirow{2}{*}{ /sælam/ } & imitation & $1149.60(54.47)$ & $1127.06(50.95)$ \\
\hline & & reading & $921.10(54.67)$ & $852.37(51.23)$ \\
\hline & \multirow{2}{*}{ /Pemruz nemiyad/ } & imitation & $1885.85(81.92)$ & $1127.06(50.95)$ \\
\hline & & reading & 2040.64 (124.73) & $852.37(51.23)$ \\
\hline \multirow{2}{*}{ sadness } & \multirow{2}{*}{ /sælam/ } & imitation & $1059.64(46.30)$ & $922.93(43.31)$ \\
\hline & & reading & $948.76(50.88)$ & $826.18(47.60)$ \\
\hline \multirow{2}{*}{ sadness } & \multirow{2}{*}{ /Pemruz nemiyad/ } & imitation & $1829.64(81.07)$ & $922.93(43.31)$ \\
\hline & & reading & $2132.89(110.86)$ & $826.18(47.60)$ \\
\hline \multirow{4}{*}{ happiness } & \multirow{2}{*}{ /sælam/ } & imitation & $1120.10(51.66)$ & $1078.53(48.32)$ \\
\hline & & reading & $978.39(53.06)$ & $865.00(49.63)$ \\
\hline & \multirow{2}{*}{ /Pemruz nemiyad/ } & imitation & $1120.10(51.66)$ & $1078.53(48.32)$ \\
\hline & & reading & $978.39(53.06)$ & $865.00(49.63)$ \\
\hline \multirow{4}{*}{ question } & \multirow{2}{*}{ /sælam/ } & imitation & $1045.78(42.21)$ & 933.68 (39.47) \\
\hline & & reading & $999.00(51.96)$ & $847.15(48.61)$ \\
\hline & \multirow{2}{*}{ /Pemruz nemiyad/ } & imitation & $1045.78(42.21)$ & $933.68(39.48)$ \\
\hline & & reading & $999.00(51.96)$ & $847.15(48.61)$ \\
\hline \multirow{4}{*}{ statement } & \multirow{2}{*}{ /sælam/ } & imitation & $1015.78(47.17)$ & $850.87(44.12)$ \\
\hline & & reading & $947.67(45.65)$ & $716.31(42.70)$ \\
\hline & \multirow{2}{*}{ /Pemruz nemiyad/ } & imitation & $1015.78(47.17)$ & $850.87(44.12)$ \\
\hline & & reading & $947.67(45.65)$ & $716.31(42.70)$ \\
\hline \multicolumn{5}{|c|}{ Table 2. Sentence duration of broadcasted sound in different moods and emotions by millisecond } \\
\hline \multicolumn{2}{|l|}{ Modes } & \multicolumn{2}{|c|}{ Task } & Duration \\
\hline \multirow{2}{*}{ exclamation } & & \multicolumn{2}{|l|}{ /sælam/ } & 1305 \\
\hline & & \multicolumn{2}{|l|}{ /Pemruz nemiyad/ } & 1527 \\
\hline \multirow{2}{*}{ sadness } & \multicolumn{3}{|c|}{ /sælam/ } & 1038 \\
\hline & & \multicolumn{2}{|l|}{ /Pemruz nemiyad/ } & 1473 \\
\hline \multirow{2}{*}{ happiness } & & /sælam/ & & 932 \\
\hline & & /Pemruz nemiyad/ & & 1799 \\
\hline \multirow{2}{*}{ question } & & /sælam/ & & 972 \\
\hline & & /Pemruz nemiyad/ & & 1370 \\
\hline \multirow{2}{*}{ statement } & & /sælam/ & & 872 \\
\hline & & /Pemruz nemiyad/ & & 1388 \\
\hline
\end{tabular}

Table 3. Variation range of duration of "/scelam/" and "/Pemruz nemiyad/" in the two groups in different moods and emotions

\begin{tabular}{|c|c|c|c|}
\hline Task & Type & Hearing & Max - Min \\
\hline \multirow{4}{*}{ /sælam/ } & \multirow{2}{*}{ Imitation } & cochlear implant & exclamation - happiness \\
\hline & & normal & happiness - exclamation \\
\hline & \multirow{2}{*}{ Reading } & cochlear implant & exclamation - happiness \\
\hline & & normal & sadness - statement \\
\hline \multirow{4}{*}{ /Pemruz nemiyad/ } & \multirow{2}{*}{ Imitation } & implant cochlear & happiness - statement \\
\hline & & normal & statement - happiness \\
\hline & \multirow{2}{*}{ Reading } & cochlear implant & happiness - sadness \\
\hline & & normal & happiness - sadness \\
\hline
\end{tabular}




\section{Discussion}

This study aims at comparing word and sentence duration in cochlear implant and normal elementary school students in imitation and reading. Hence, the word "/sælam/" and the sentence "/Pemruz nemiyad/" were chosen because they are used in everyday speaking, they are not dependent on the subjects level of knowledge, they are short, and they can be measured quickly.

The results showed that mean duration of "/sælam/" in cochlear implant children in all moods and emotions (exclamation, sadness, happiness, question, and statement) is significantly longer than in normal hearing children both in imitation and reading.

It was observed that mean duration of "/sælam/" in both groups in all modes is shorter in reading as compared to imitation, which maybe because the test is a one-word that is considered as an everyday use with which the subjects are familiar. In other words, this result is because the participant reads the word in a short time in the process of reading the whole word while in imitation, the subject tries to imitate the speech pattern which $\mathrm{s} /$ he has heard and that causes the contestant to imitate the one-word slower than when $\mathrm{s} /$ he tries to read it.

The results also showed that the mean duration of "Pemruz nemiyad/" in cochlear implant children is longer than in normal hearing children in all modes of imitation and reading.

The mean duration of the sentence "/Pemruz nemiyad/" in cochlear implant group is longer in reading as compared to imitation, contrary to the result of reading the word "/sælam/" where the distance between the reading curve of the two groups is low. In reading the sentence "/Pemruz nemiyad/", the distance between the curve of the two groups has been much bigger - which shows that the cochlear implant group takes a much longer duration in reading the sentence than the normal hearing group. It can be deducted that since the sentence is composed of two words and there is a long pause between the two words, cochlear implant children take a much longer duration to finish reading the sentence. of . This is because one of the features of speech prosody in children with hearing impairment is long pauses (Clark, 2007), while in imitation, the subject imitates the pattern which is not much paused. Moreover, as discussed by Clark, as the number of the syllables increases, the duration needed by cochlear implant children becomes longer than that needed by normal children.. Thus, the increase in number of the syllables in the sentence "/Pemruz nemiyad/" can be another reason for the duration difference between the two groups. (Clark, 2007).

The results of the present study show that the mean duration of cochlear implant children in all tasks is longer than in normal children. Kord et al. have also indicated that the mean duration of cochlear implant children in question and statement moods is significantly longer than normal hearing children (Kord, Shahbodaghi, Khodami, Nourbakhsh, \& Jalaei, 2013). Jafary's study also indicated that cochlear implant children's duration of the Persian language vowels is longer than normal children (Jafary, Yadegari, \& Torabineghad, 2014).

The present study as well as Clark's study indicated that the duration needed by cochlear implant children speech, particularly when the number of the syllables increases, is longer than that needed by normal children (Clark, 2007). The results of the study of Vandam et al. indicated that vowel duration in words pronounced by cochlear implant children is longer than that in normal children (Vandam, Ide-Helvie, \& Moeller, 2011). Also, Uchanski and Geers indicated that vowel duration in sentences said by cochlear implant children is longer than normal hearing children (Uchanski \& Geers, 2003). In a study, O'Halpin indicated that speech duration in cochlear implant children is significantly longer than in normal children (O’Halpin, 2010). Levitt and Obseger indicated that vowel duration in the group with severe hearing impairment is longer than in the normal hearing group (Osberger \& Levitt, 1979).

Hence, the results of the present study are the same as previous studies and all indicate that mean duration of speech in cochlear implant children is longer than 
in normal children. The analysis of mean duration in the cochlear implant group in different moods and emotions indicated that the mean duration is different in different modes of the word "/sælam/" and the sentence "/Pemruz nemiyad/" in such a way that the longest duration in the word "/sælam/" was that of imitation with exclamation emotion, and the shortest was that of reading in exclamation emotion. Also, the longest duration in the sentence "/Pemruz nemiyad/" was that of reading in sad emotion, and the lowest was that of imitating in statement mood. The mean duration of different modes of the aforementioned word and sentence in normal group also showed different values, such that the longest word duration in this group was that of imitation with exclamation emotion, and the lowest was that of reading in statement mood. Also, the longest sentence duration was that of imitation with happy emotion, and the lowest was that of reading in statement mood. Therefore, it can be deducted that a word or a sentence in different modes (exclamation, sadness, happiness, question, and statement) has different durations and one factor that affects speech duration is its emotional state. Nikravesh has also indicated that different moods of a sentence have different durations as well (Nikravesh, 2010).

In addition to studying the mean duration between the two groups, the present study also aims at finding an answer to the following question: Will the duration disorder in cochlear implant children be improved by giving an appropriate duration pattern in imitation mode?

The longest mean duration (tables $2 \& 3$ ) in the two groups in imitating "/sælam/" was that of exclamation emotion, and the longest mean duration of " Pemruz nemiyad/" was that of happy emotion - which is completely similar to the longest duration of the broadcasted sounds in the word and the sentence. Also, the lowest mean duration in the two groups in imitating both tasks (imitation and reading) was similar to one another and different from the broadcasted sound. The lowest duration of "/sælam/" in the two groups was that of happy emotion, and in broadcasted sound was that of statement tone. Also, the lowest duration of "/Pemruz nemiyad/" in the two groups was that of statement mood, and in the broadcasted sound, it was that of question mood. The cochlear implant group had a relatively similar performance to that of the normal group in imitating the word and the sentence, in such a way that the longest and lowest duration in the two groups in the given tasks is similar and there is no meaningful difference between the variation ranges of the two groups. On this basis, it can be understood that when the duration of the given task is long, the cochlear implant group as well as the normal group is able to imitate it properly, while when the duration of the given task is short, neither of the two groups are able to imitate it. Therefore, it can be deducted that both groups have probably understood the notion of duration and were trying to imitate it, but they could not adjust its level.

Since duration is one of the main components of speech intonation and any damage to it results in defect(s) in intonation and decreases speech clarity of these children, in the present study, duration was studied as a prosodic element. The present study aimed at presenting an appropriate solution to decrease duration, and hence enhancing the intonation and speech clarity of cochlear implant children. For this purpose, the imitation therapeutic method was applied, but the results indicated that cochlear implant children's performance in imitation differs depending on the type of the task and its emotional state. Therefore, it can be said that the imitation method is probably not an appropriate method to improve duration in these children and hence more appropriate methods should be looked for.

\section{Conclusion}

In general, the duration of speech in cochlear implant children in various emotional states, in imitation and reading, is longer than normal hearing children. Although cochlear implant children's performance in imitation is relatively similar to normal hearing children, but their performance in reading is very different and their mean duration of speech, particularly as the number of the syllables increases, is much longer than normal group which could be probably 
due to patterns being internal - which exposes itself more in reading. CI children's longer duration results in disruption of their speech intonation. Although the results showed that the imitation method does not cause cochlear implant children to follow speaker's duration as they should, but when the duration of the given tasks is long, cochlear implant children are able to imitate it. Hence, it is suggested that the therapists who deal with such children begin the treatment from the highest level of duration if they utilize imitation method for modifying duration.

\section{References}

Afshar, M. R., Qorbani, A. Jalilevan, N., \& Kamil, M. (2013). Providing the Non-Word Repetition test and determining its validity and reliability and comparing phonological working memory in 4 to 6 Farsi-speaking normal and SSD children in Tehran City. Rehabilitation Sciences, 9(5).

Calmels, M. N., Saliba, I., Wanna, G., Cochard, N., Fillaux, J., Deguine, O., \& Fraysse, B. (2004). Speech perception and speech intelligibility in children after cochlear implantation. International journal of pediatric otorhinolaryngology, 68(3), 347-351.

Carter, A. K., Dillon, C. M., \& Pisoni, D. B. (2002). Imitation of nonwords by hearing impaired children with cochlear implants: Suprasegmental analyses. Clinical Linguistics \& Phonetics, 16(8), 619-638.

Casserly, E. D., \& Pisoni, D. B. (2013). Nonword repetition as a predictor of long-term speech and language skills in children with cochlear implants. Otology \& neurotology: official publication of the American Otological Society, American Neurotology Society [and] European Academy of Otology and Neurotology, 34(3), 460.

Chen, Y., Wong, L. L., Chen, F., \& Xi, X. (2014). Tone and sentence perception in young Mandarin-speaking children with cochlear implants. International journal of pediatric otorhinolaryngology, 78(11), 1923-1930.

Corbetta, L. K., Danhauer, J. L., \& Prutting, C. A. (1990). A young meningitically deaf child with a cochlear implant: a case study. International journal of pediatric otorhinolaryngology, 20(1), 25-43.

Corriveau, K. H., Goswami, U., \& Thomson, J. M.

\section{Acknowledgments}

This research was supported by grants provided from Department of Speech \& Language phytology, affiliated to Iran University of Medical Sciences.

\section{Conflict of Interest}

Authors declared no conflict of interest.

(2010). Auditory processing and early literacy skills in a preschool and kindergarten population. Journal of learning disabilities, 43(4), 369-382.

Dawson, P., Busby, P., McKay, C., \& Clark, G. M. (2002). Short-term auditory memory in children using cochlear implants and its relevance to receptive language. Journal of Speech, Language, and Hearing Research, 45(4), 789-801.

Dillon, C. M., Burkholder, R. A., Cleary, M., \& Pisoni, D. B. (2004). Nonword Repetition by Children With Cochlear ImplantsAccuracy Ratings From Normal-Hearing Listeners. Journal of Speech, Language, and Hearing Research, 47(5), 1103-1116.

Fallon, M., Peelle, J. E., \& Wingfield, A. (2006). Spoken sentence processing in young and older adults modulated by task demands: evidence from self-paced listening. The Journals of Gerontology Series B: Psychological Sciences and Social Sciences, 61(1), P10-P17.

Hasanzadeh, S., \& Minaiee, A. (2001). Adaptation and standardization of language development test TOLD-P: 3 for persian language children. Tehran: Research on exceptional children.

Henry, B. A., Turner, C. W., \& Behrens, A. (2005). Spectral peak resolution and speech recognition in quiet: normal hearing, hearing impaired, and cochlear implant listeners. The Journal of the Acoustical Society of America, 118(2), 1111-1121.

Huttenlocher, J., Vasilyeva, M., Cymerman, E., \& Levine, S. (2002). Language input and child syntax. Cognitive psychology, 45(3), 337-374.

Ibertsson, T., Willstedt-Svensson, U., Radeborg, K., \& 
Sahlén, B. (2008). A methodological contribution to the assessment of nonword repetition - a comparison between children with specific language impairment and hearing-impaired children with hearing aids or cochlear implants. Logopedics Phoniatrics Vocology, 33(4), 168178.

Jiménez, M. S., Pino, M. J., \& Herruzo, J. (2009). A comparative study of speech development between deaf children with cochlear implants who have been educated with spoken or spoken+ sign language. International journal of pediatric otorhinolaryngology, 73(1), 109-114.

Lee, Y., Yim, D., \& Sim, H. (2012). Phonological processing skills and its relevance to receptive vocabulary development in children with early cochlear implantation. International Journal of Pediatric Otorhinolaryngology, 76(12), 1755-1760.

Lina-Granade, G., Comte-Gervais, I., Gippon, L., Nappez, G., Morin, E., \& Truy, E. (2010). Correlation between cognitive abilities and language level in cochlear implanted children. Cochlear implants international, 11(sup1), 327-331.

Löfkvist, U., Almkvist, O., Lyxell, B., \& Tallberg, M. (2014). Lexical and semantic ability in groups of children with cochlear implants, language impairment and autism spectrum disorder. International journal of pediatric otorhinolaryngology, 78(2), 253-263.

Mandal, J. C., Kumar, S., \& Roy, S. (2016). Comparison of auditory comprehension skills in children with cochlear implant and typically developing children. International journal of pediatric otorhinolaryngology, 91, $113-120$

McKinlay, A. (2011). Vineland Adaptive Behavior Scale. Encyclopedia of Child Behavior and Development. New York: Springer, 1544-1545. https://doi. org/10.1007/978-0-387-79948-3_1602

Mohamadi, R., Alavije, M. R., Minayi, A., Modaresi, Y., Dastjerdi, M. K., \& Ghaderi, M. (2015). Generation and Content Validation of a Persian Syntax Comprehension Test. Psychology of Language and Communication, 19(3), 222-236.

Nittrouer, S., Caldwell, A., Lowenstein, J. H., Tarr, E.,
\& MHolloman C. (2012). Emergent literacy in kindergartners with cochlear implants. Ear and hearing, 33(6), 683.

Percy-Smith, L., Busch, G., Sandahl, M., Nissen, L., Josvassen, J. L., Lange, T., Rusch, E., \& Cayé-Thomasen, P. (2013). Language understanding and vocabulary of early cochlear implanted children. International journal of pediatric otorhinolaryngology, 77(2), 184-188.

Pisoni, D. B., \& Cleary, M. (2003). Measures of working memory span and verbal rehearsal speed in deaf children after cochlear implantation. Ear and hearing, 24(1 Suppl), 106S.

Razavieh, A., \& Shahim, S. (1990). Adaptation and standardization of Wechsler Preschool and Primary Scale of Intelligence in Iran. Journal of Social Sciences and Humanities, Shiraz University, 10, 49-74. Retrieved from

Soleymani, Z., Amidfar, M., Dadgar, H., \& Jalaie, S. (2014). Working memory in Farsi-speaking children with normal development and cochlear implant. International journal of pediatric otorhinolaryngology, 78(4), 674-678.

Willis, S., Goldbart, J., \& Stansfield, J. (2014). The strengths and weaknesses in verbal short-term memory and visual working memory in children with hearing impairment and additional language learning difficulties. International journal of pediatric otorhinolaryngology, 78(7), 1107-1114.

Willstedt-Svensson, U., Löfqvist, A., Almqvist, B., \& Sahlén, B. (2004). Is age at implant the only factor that counts? The influence of working memory on lexical and grammatical development in children with cochlear implants. International journal of audiology, 43(9),506-515.

Wingfield, A., \& Tun, P. A. (2001). Spoken language comprehension in older adults: Interactions between sensory and cognitive change in normal aging. Seminars in Hearing, Copyright $\subset 2001$ by Thieme Medical Publishers, Inc., 333 Seventh Avenue, New York. 

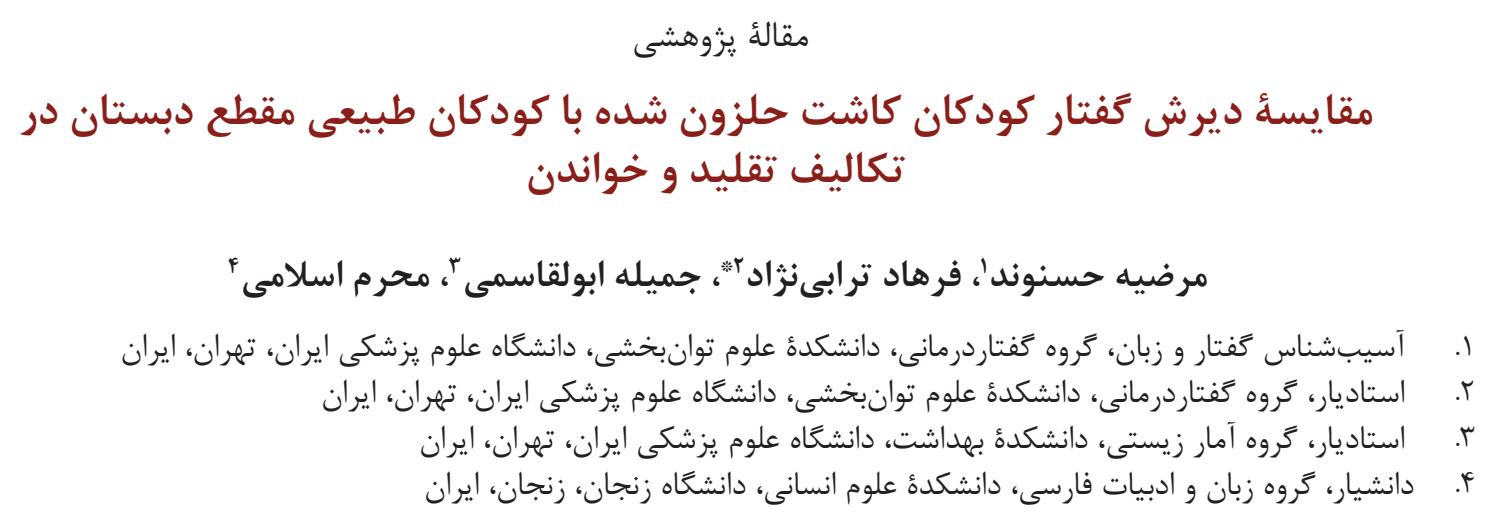

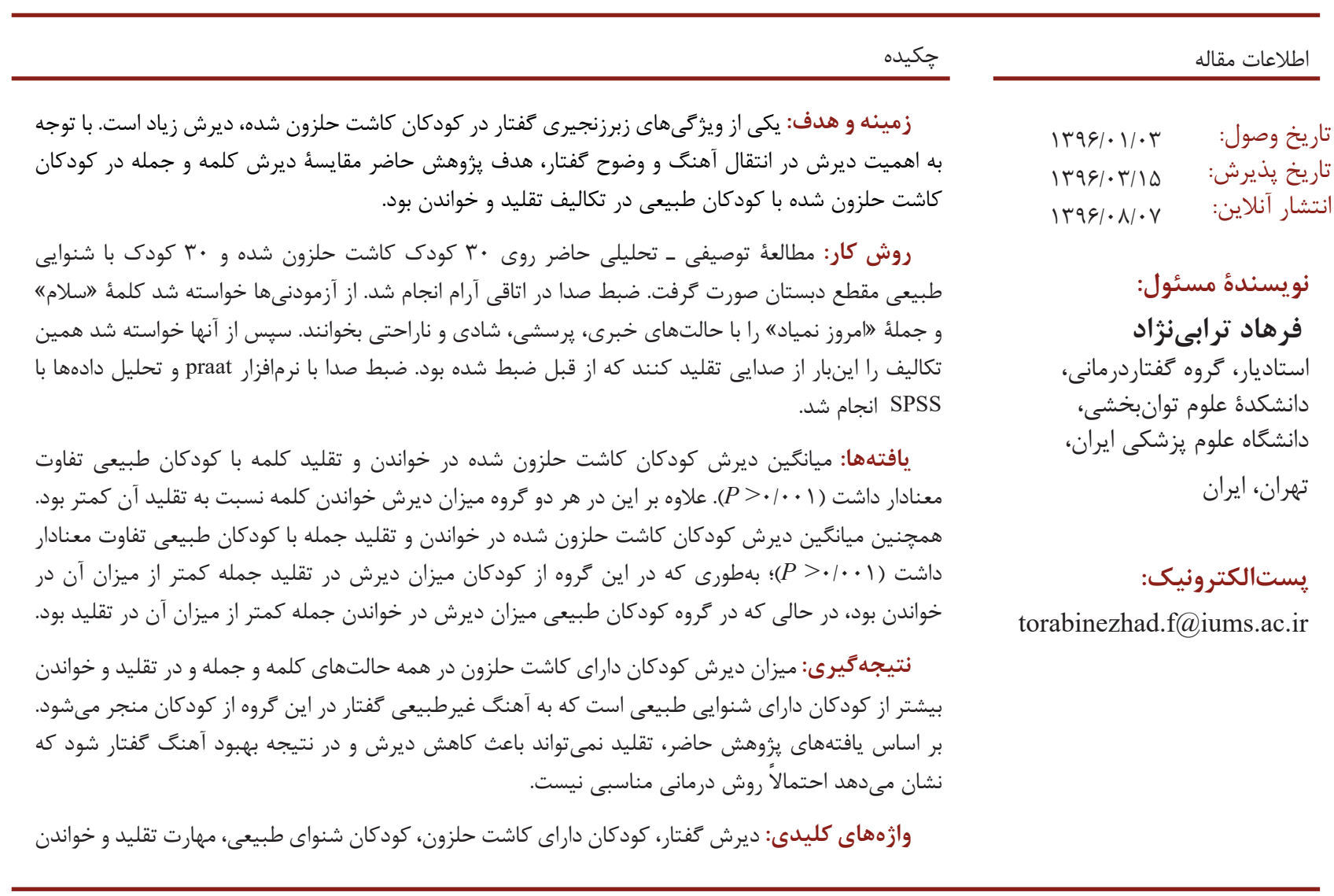

